\title{
IRT research on influence of long-term loads on defects in FRP strengthened RC beams
}

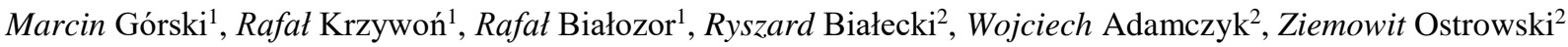 \\ ${ }^{1}$ Silesian University of Technology, Faculty of Civil Eng., Department of Structural Eng., ul. Akademicka 5, 44-100 Gliwice, Poland. \\ ${ }^{2}$ Silesian University of Technology, Institute of Thermal Technology, Konarskiego 22, 44-100 Gliwice, Poland.
}

\begin{abstract}
It has been more than two decades, since FRP strengthening method was first time used in Poland. Therefore there is a natural need to develop an efficient quality assessment technique to verify design assumptions of strengthening in existing structures after many years. One of the promising non-destructive method of quality assessment is infrared thermography (IRT). In this paper, an initial study on recognition of delamination mainly in CFRP laminates using IRT was conducted as well as the influence of long-term loads on defects in CFRP strengthened RC beams was presented.
\end{abstract}

\section{Introduction}

One of the most popular strengthening method is using Fiber Reinforced Polymer (FRP). It has been more than two decades since those methods were first time used in industry. The first application of Carbon Fiber Reinforced Polymer (CFRP) strips in bridge industry in Poland took place in Przemyśl on bridge structure at Wiar river in 1997 [1]. Since then, many bridge structures in Poland has been strengthened using FRP technique and, as a consequence, it has been widely spread across the country. Many improvements such as an initial pre-tensioning were introduced and developed for increasing of serviceability as well as the load bearing capacity of structural members [1]. After many years of using those strengthening techniques it is also required to use efficient methods of quality assessment of connections between strengthened member and composite, not only during construction stage but also during periodic inspections of existing structures [2]. It is especially important for structures under long-term loads. Connections between composite and surface of structural member prepared in a regardless way can lead to hidden defects or voids as well as discontinuities in the bonding layer. As a consequence, it can result in local delamination of material which means that composite connection does not meet required criteria anymore.

\subsection{Standard quality assessment methods}

Currently used quality assessment of bonding layer of strengthening composites is usually limited to visual inspection and initial destructive methods during the construction stage. Initial destructive methods are based on bonding small parts of CFRP strips to the surface of the structural member. The control surface is prepared in the same way but is located beyond the target surface of the bonding.

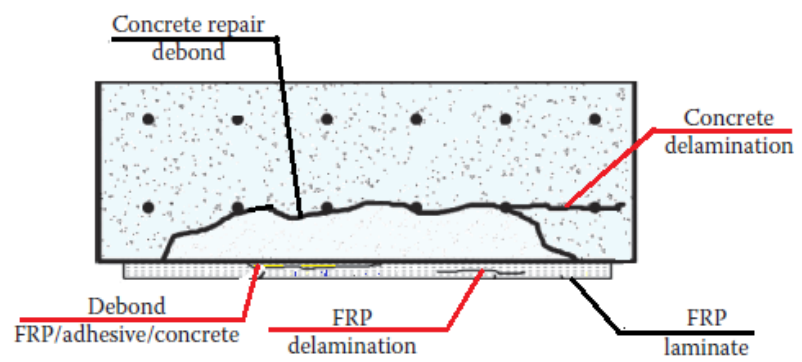

Fig. 1. Location of potential degradation in FRP strengthened structural member [3].

Pull-off tests are performed on such prepared samples. Results of the tests are considered as a positive, when the rupture of the sample occurred in concrete. Based on this tests the proper level of bonding is assumed which depends on many factors. There are also some difficulties with assessment of bonding state of CFRP during periodic inspections.

\subsection{Thermography as one of non - destructive methods}

For inspections of composite structures also nondestructive methods are used such as acoustic, radiographic and ultrasonic testing [4]. Among them, a method of infrared thermography can be found. Methods of thermography directed to the identification of discontinuities in a bonding layer of composite are a subject of a few studies all around the world [5-7]. So far, none of them was directed to structural members strengthened with FRP and estimation of the load bearing capacity based on quality and the current state of the

\footnotetext{
* Corresponding author: marcin.gorski @ polsl.pl
} 
bonding layer. It is especially important, when during the inspection it has to be decided, if the strengthened structural member is still able to carry the load. Therefore, it was decided to study the influence of long-term loads on defects in FRP strengthened concrete beams. This study is mainly focused on laminates based on carbon fibers.

\section{FRP strengthened RC beams under long-term load}

Experimental program on long-term behaviour consist of RC beam, strengthened with CFRP strip type $S$ \& P CFK Lamellen 200/2000 60x1.4 mm. This type of strengthening was adhered to the bottom surface of beam with Sikadur ${ }^{\circledR} 330$ adhesive.

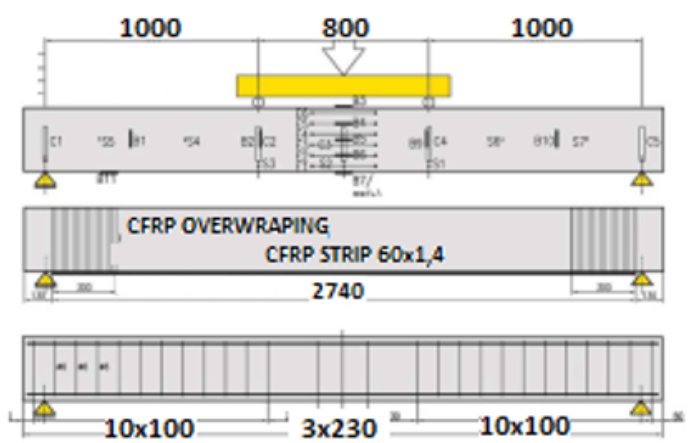

Fig. 2. RC beam geometry used for a test [8]

Beam was made of concrete of the guaranteed class $\mathrm{C} 25 / 30$. Its properties determined in the laboratory tests are: the average concrete cube strength $44.7 \mathrm{MPa}$, the modulus of elasticity of $31 \mathrm{GPa}$ and tensile strength in the Brazilian test $3.20 \mathrm{MPa}$. The main reinforcement of beams consists of three \#12 bars in the bottom (tension) zone and two \#8 top bars (Fig. 2). As the shear reinforcement \#6 stirrups were used in the $100 \mathrm{~mm}$ spacing. The tensile strength of the \#12 steel specified in the tests was $660.8 \mathrm{MPa}$, yield strength $570.06 \mathrm{MPa}$, modulus of elasticity $200.7 \mathrm{GPa}$.

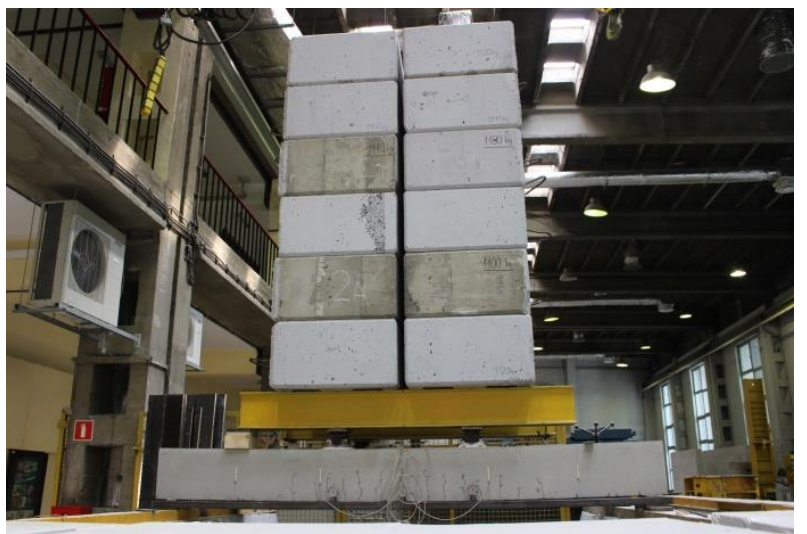

Fig. 3. Side view of laboratory long-term tests.
All beams were tested in the four-point bending test. The load was applied in the form of concrete blocks with a total weight exceeding 13 tonnes. This is about $67.7 \mathrm{kN}$ per each beam, around $50 \%$ of observed real failure force and $80 \%$ of force which causes the yield of reinforcement. In authors opinion, such a value corresponds to the real conditions of long-term maintenance of this type of construction.

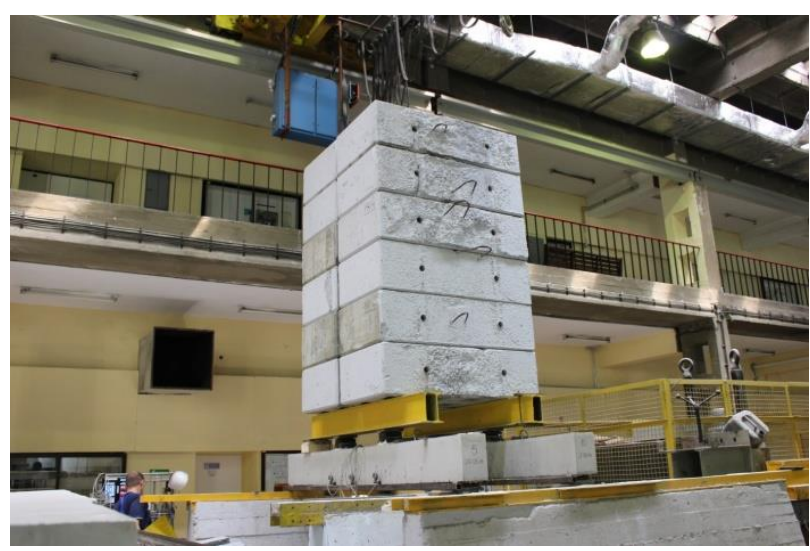

Fig. 4. Front view of laboratory long-term tests.

During the tests (Fig 3-4) the deflection was measured in the middle of the span, at the supports and at the ends of the constant moment segment (analogue indicators), deformation of concrete and composite overlays in the plane section of the maximum bending moment and in the anchoring zone (strain gauges and analogue extensometer).

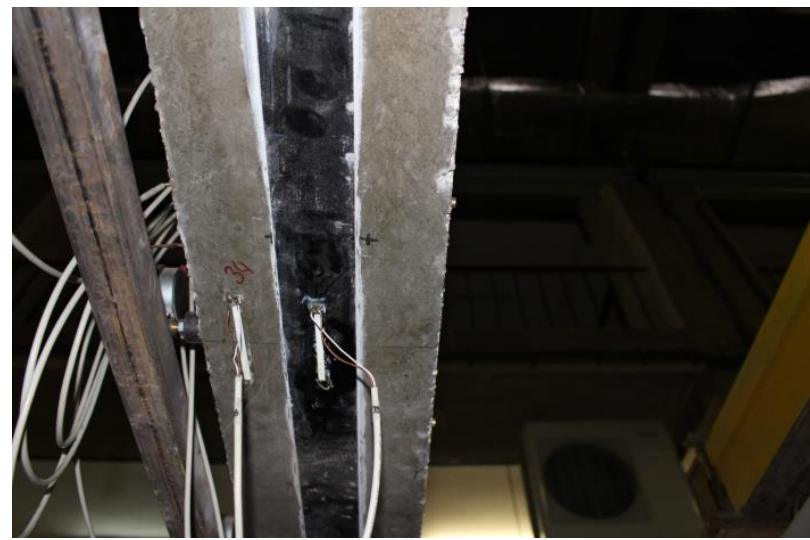

Fig. 5. CFRP strip on the bottom surface of RC beam.

The main objective of this research was to check CFRP reinforcement efficiency in the reduction of deflections for long-term loads (Fig. 5), as well as observation of defects development. The beams were tested for a period of two years. The readings were initially carried out at weekly intervals, the average monthly increase in deflections does not exceed $0.2 \mathrm{~mm}$, therefore, after six months the frequency of readings was reduced to a month. Figure 6 shows the graph of the growth of the beam's deflection as a function of load time. 


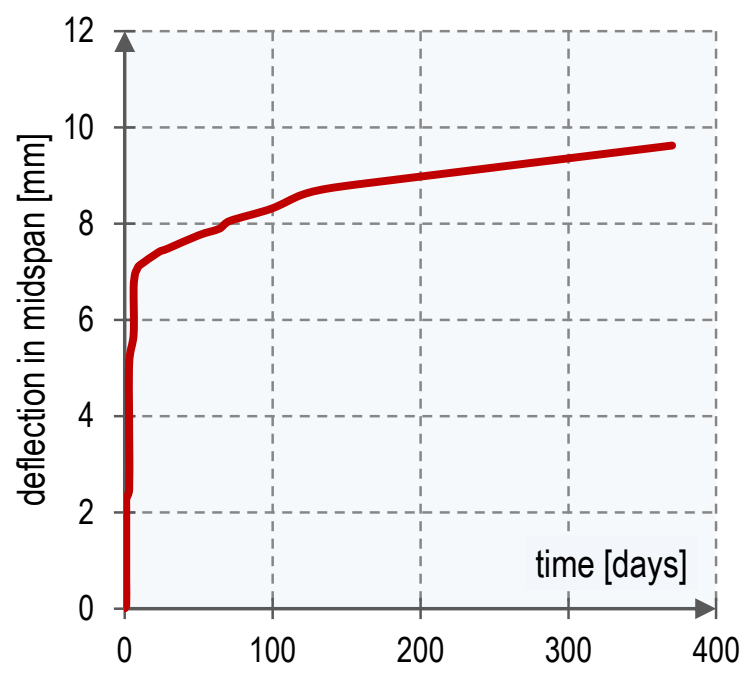

Fig. 6. Deflection of RC strengthened beam as a time function

The average crack spacing for the beam it is $140 \mathrm{~mm}$. The crack opening in this case, does not exceed $0.1 \mathrm{~mm}$. The range of the cracking zone practically does not change in time, the observed crack image has been stabilized in the first two weeks, and no new cracks appeared.

\section{Thermography Tests}

\subsection{Preparation and Initial Tests}

The initial thermographic study was performed and calibrated with use of FLIR camera type. Images were recorded with resolution of $640 \times 460$ with the frequency of 9-30 Hz. The testing surface was covered with thin layer of graphite paint in order to limit the reflectivity and minimize the effect of heat emissivity on the camera readings. The temperature gradient between object and environment was forced by using convective electric heater with control of both temperature and blowing intensity. Measurement methodology was as follows: after thermal excitation thermograms were recorded within $1 \mathrm{~min}$. Recorded images were processed using an self-made LabVIEW application producing information on material delamination of FRP or/and concrete cracking. Initial tests were performed on concrete blocks of 30x30cm with two CFRP samples (Fig. 7), one with artificially prepared defect. It can be observed (Fig. 8) that process of the surface cooling was slower in place where defect was prepared.

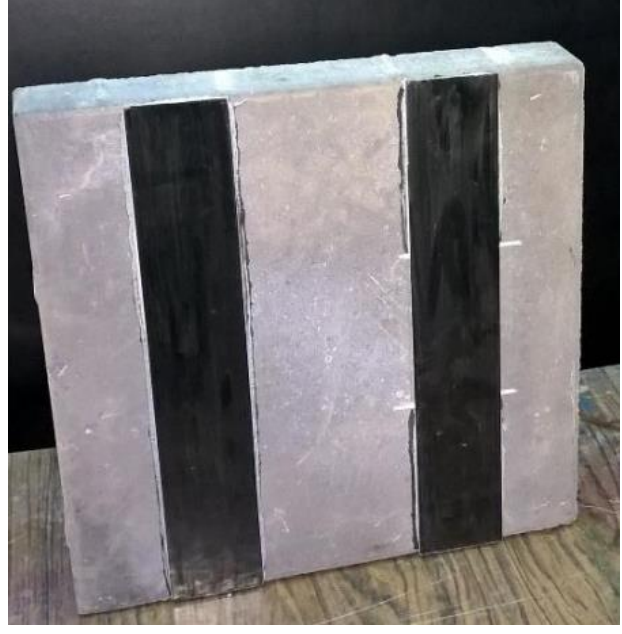

Fig. 7. Specimen of CFRP strips for initial thrmography tests

a)

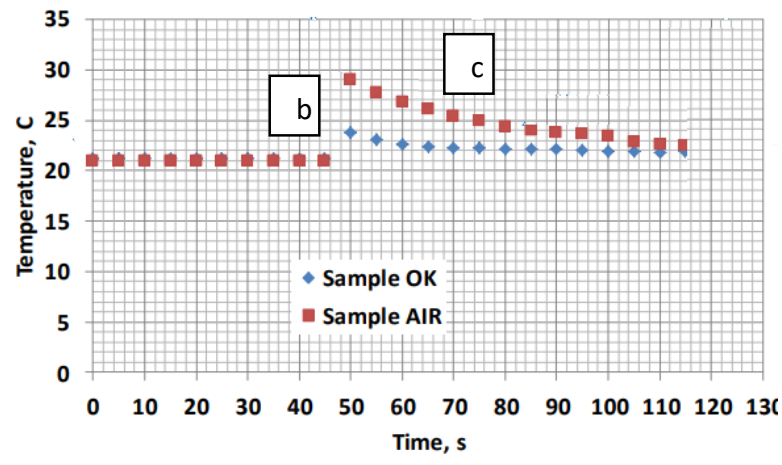

b)

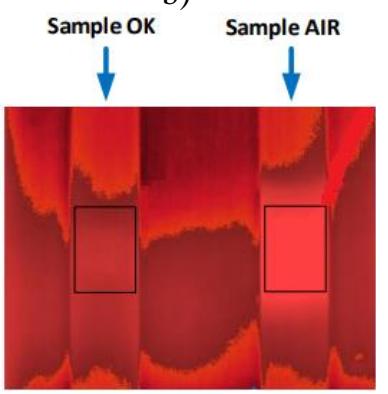

c)

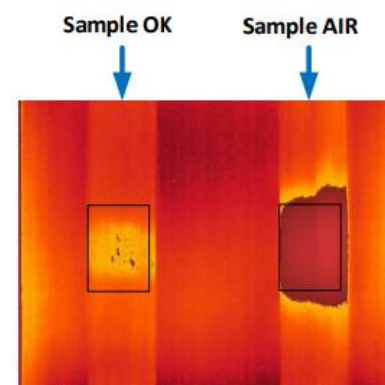

Fig. 8. Time - history of thermal behaviour of specimen a) comparison of thermographic images of specimen just after heating $b$ ) and during cooling process c).

\subsection{Thermographic tests on long-term loaded beams}

In this case, the thermographic analysis was performed in the same manner as the initial study. Thermographic images have been taken along the beam every 30 centimetres. Two examples of thermograms were shown in figure 9. The first picture presents temperature field just after heating and the second 20 seconds later. Images were recorded using the same scale of temperature. Bright areas indicate a worse quality of bonding of FRP with the structural member. Even just after heating non-uniform distribution of temperature gradient can be distinguish as a result of different contact between CFRP and concrete. 

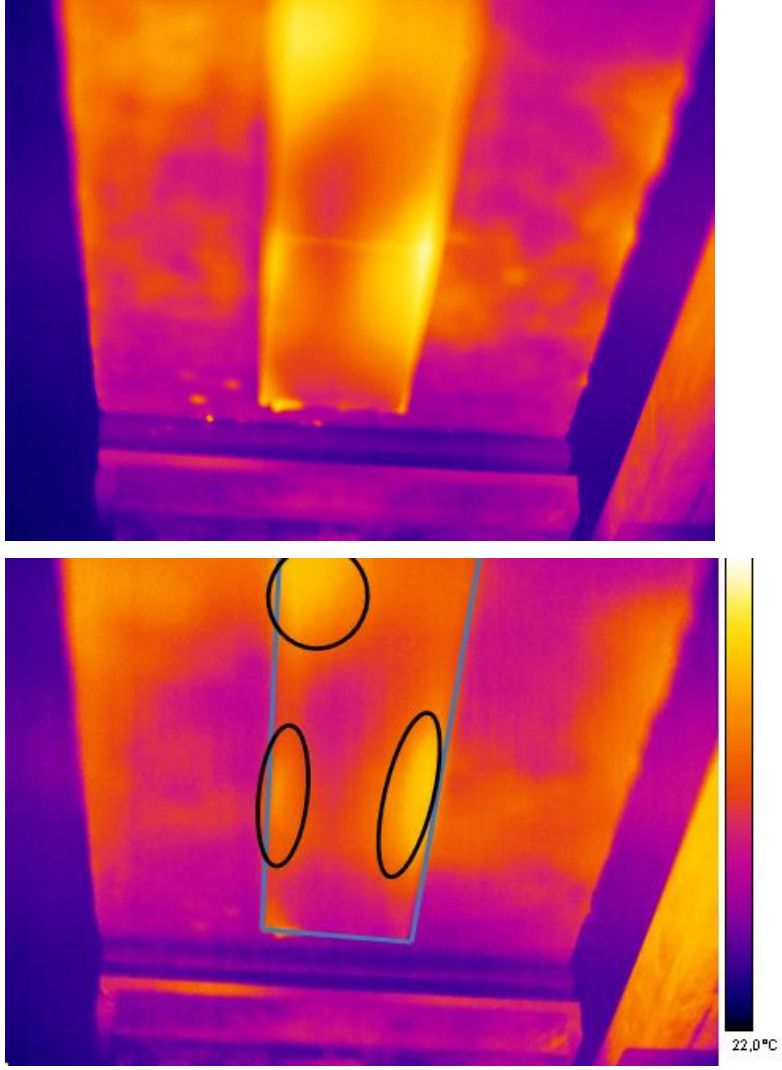

Fig. 9. Comparison of thermographic images of strengthened beams just after heating a) and during cooling process $b$ ).

The similar defects were observed in a few places along the beam. The estimated area of potential defects is up to $6.4 \%$ of total area of the initial bonding layer. Assuming that this area is not taken into account in load bearing, it can be simply estimated that moment bearing capacity is about 3\% lower compared to a member without any defects.

\section{Summary}

Based on results obtained in the presented study, the following conclusions can be drawn:

- IRT techniques can be successfully applied as a nondestructive method of inspections of FRP strengthened RC structural members,

- during loading of RC beams potential areas of delamination or debonding occurred and it was indicated using IRT method.

Further research will be directed to the more accurate estimation of load bearing capacity of structural members strengthened with CFRP when defects and delamination occur on thermographic images as well as the application of these methods under on-site conditions. Basic issue in the detection of defects in real concrete structures (e.g. bridges) by IRT is application of proper heating system. A phenomenon is also reported in literature [9].

\section{References}

1. Siwowski T.: Wzmacnianie mostów materiałami kompozytowymi, 2017, published online at www.izbudujemy.pl (available 20.03.2018).

2. Mtenga P.V., Limerick R.L., Tawfiq K.S.: IRT Evaluation of Bond Layer Thickness for CFRP Bonded To Concrete, 2018

3. Zoghi M.: The International Handbook of FRP Composites in Civil Engineering, CRC Press, Taylor \& Francis Group, Boca Raton, 2014.

4. Waugh R., Development of Infrared Techniques for Practical Defect Identification in Bonded Joints, Springer International Publishing, Switzerland, 2016,

5. Corvaglia P., Largo A.: IRT survey for the quality control of FRP reinforced r.c. structures, 9th International Conference on Quantitative InfraRed Thermography, Krakow, 2008

6. Delpak R., Shih J.K.C., Hu C. W and Tann D. B.: Detection of air blisters and crack propagation in FRP strengthened concrete elements using infrared thermography, InfraMation - The Thermographers Conference, 2002.

7. Delpak R., Shih J.K.C., Andreou E., Hu C. W and Tann D. B.: Thermographic Blister Detection in FRP Strengthened RC Elements and Degradation Effects on Section Performance in FRP Composites in Civil Engineering, Teng, J. G., Elsevier, pp. 1135-1142, 2001.

8. Krzywoń R., Górski M., Dawczyński S.: Features of SRP tapes against CFRP composites used for strengthening of concrete structures, International Conference on Analytical Models and New Concepts in Concrete and Masonry Structures AMCM'2017.

9. Milovanović B., Pecur I., Review of Active IR Thermography for Detection and Characterization of Defects in Reinforced Concrete, Journal of Imaging No.02, 2016

\section{Acknowledgments}

The research programme referred to in this paper has been supported by the Polish Ministry of Science and Higher Education (Grant No. BK-235/RB6/2017) and statutory research funds of the Faculty of Energy and Environmental Engineering, Silesian University of Technology. 